\title{
Democracy, information, and libraries in a time of post-truth discourse
}

Peter Johan Lor

University of Pretoria, South Africa

University of Wisconsin-Milwaukee, USA

\begin{abstract}
Purpose - To serve their clients in a time of post-truth discourse and fake news, librarians need to understand the post-truth phenomenon. The purpose of this article is to examine it, what is being done in response to it, and specifically what libraries can do.

Design/methodology/approach - Recent literature on the post-truth phenomenon was examined. Traditional assumptions about the role of libraries in promoting democracy were questioned and an alternative view was put forward. Libraries' responses to the post-truth phenomenon were examined and critically discussed.

Findings - Traditional assumptions about the role of libraries and information and democracy are outdated. The susceptibility of people to false beliefs and the persistence of these beliefs in spite of corrective information, is the product of many factors, including the evolving media ecosystem and psychosocial processes which are the subject of ongoing empirical research. It not primarily an information or knowledge deficit, hence there are no simple antidotes to fake news. Libraries need to rethink their responses.
\end{abstract}

Research limitations - The article deals with very recent developments and relies heavily on informal online resources.

Practical implications - Relevant library activities are examined and suggestions are made for developing appropriate library responses.

Originality/value - At time of writing this was the first attempt in the library management literature to engage in a systematic and thoughtful manner with the literature on the post-truth phenomenon.

Keywords: Libraries, Information, Post-truth, Fake news, Propaganda, Social media, Media ecosystem, Social psychology, False beliefs, Fact checking, Corrective information, Information literacy

Paper type: Conceptual paper

\section{Introduction}

It has long been assumed that libraries are good for democracy. In Anglo-American librarianship especially, it is thought that libraries support democracy through the provision of information for civil discourse. In the preface to her book, Libraries \& democracy: the cornerstones of liberty, Nancy Kranich (2001a, p. v) wrote:

Democracies need libraries. An informed public constitutes the very foundation of democracy; after all, democracies are about discourse - discourse among the people. If a free society is to survive, it must ensure the preservation of its records and provide free and open access to this information to all its citizens.

Kranich's statement is one in a long line of ringing pronouncements, some of which are cited in chapters of her book. Many others are cited on a web page of the American Library Association (Kranich, 2001b). All of these embody a chain of assumptions, which are depicted schematically in Figure 1. 
Figure 1: Assumptions about relationships between libraries, information and democracy

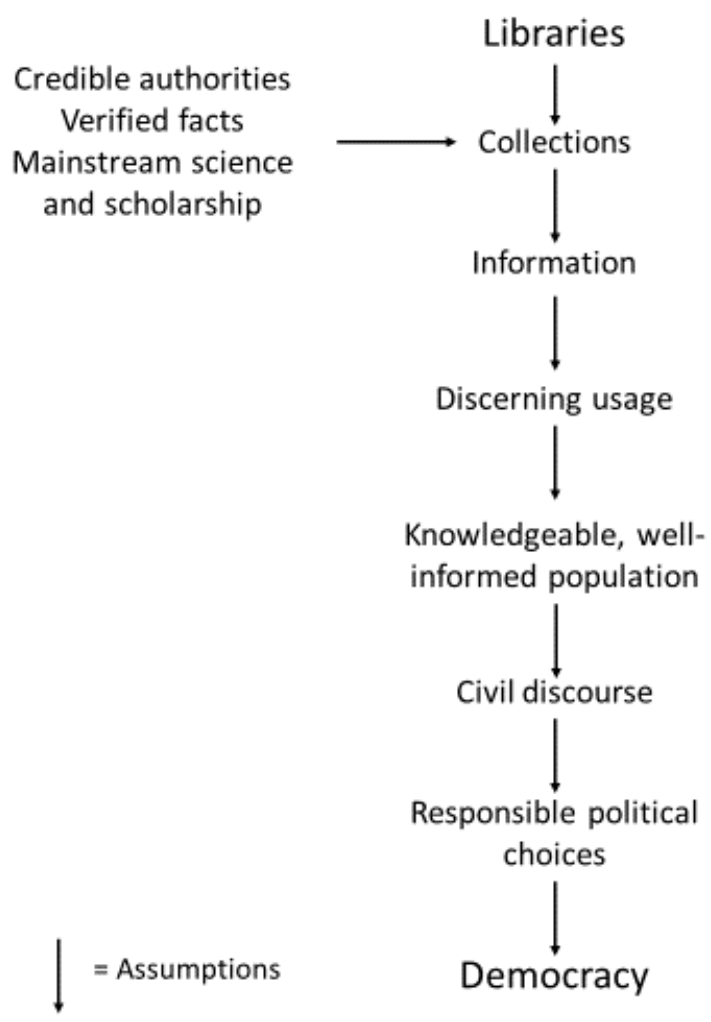

Figure produced using MS PowerPoint, copy of PowerPoint file attached

Figure 1 suggests that libraries contribute to democracy by providing selected resources from which discerning users can glean information that enables them to contribute as wellinformed citizens to civil discourse leading to responsible political choices. These assumptions can be questioned, and one is particularly problematic today: the assumption that information that is accessed by citizens will largely be truthful, or of verifiable truthfulness. What happens when the truthfulness of the information is no longer considered to be a significant factor in political discourse - when we find ourselves in what is now being called a post-truth world?

At the end of 2016 the Oxford Dictionaries announced that the adjective 'post-truth' had been chosen as the "Word of the Year 2016", and defined it as "relating to or denoting circumstances in which objective facts are less influential in shaping public opinion than appeals to emotion and personal belief". The word was used as early as the 1990s, but came into prominence in 2016 (Oxford Dictionaries, 2017).

This article examines the "post-truth" phenomenon: its manifestations and possible causes, what is being done in response to it, and more specifically what libraries are doing and can do. If much of what follows relates to the situation in the UK and the USA, that is because much of the recent evidence and comment emanates from those countries. The post-truth 
phenomenon has recently appeared there in its most startling guise. Furthermore, what happens in the USA is quite likely to spread elsewhere.

\section{Libraries, Brexit, and Trump}

In the West, the establishment and maturing of democracy was accompanied by an impressive flowering of libraries, especially public libraries. This was particularly the case in Britain and the United States. In 2016, the United Kingdom had 3,765 council-run public libraries (BBC news, 2016). The USA has almost 120,000 libraries. These include 8,895 public libraries, not counting 7,641 branches and bookmobiles (American Library Association, 2017).

However, the large number and wide accessibility of libraries in these two countries did not prevent voters there from making startling political choices, in which truthful factual information seems to have played a minor role. In the UK, emotional politics were at the centre of the Brexit (British exit from the European Union) referendum, while facts and statistics put forward by economists, bankers, and other experts were dismissed contemptuously: leave campaigner Michael Gove, at the time a cabinet minister, was reported as saying "I think people in this country have had enough of experts" (Bhattacharya, 2016). Since the Brexit referendum, journalists and political scientists have commented on the important role of emotion, identifying a widespread disregard for facts in the campaigns, especially, but not exclusively, in the Leave campaign (e.g. Chaffin, 2016; Wahl-Jorgensen, 2016).

In the USA's presidential election the winning candidate was, to put it bluntly, a prolific liar.[1] According to the respected fact-checking organization, Politifact, Mr Trump was elected following a campaign in which 70 percent of his statements were rated "mostly false," "false" or "pants on fire" (Luu, 2016). The Fact Checker blog of the Washington Post examined 168 claims made during the election campaign by Mr Trump and Mrs Clinton and gave Mr Trump 59 "Four-Pinocchio" ratings against seven for Mrs Clinton.[2] It was observed that false statements were repeatedly exposed by various fact-checking organizations, but in Mr Trump's campaign egregious lies were simply repeated, and proTrump voters did not seem to care (Wang, 2016). Luu (2016) commented: "Like hiding a book in plain sight among other books, the cumulative effect of so many obvious falsehoods, one after another, seems to have watered down any serious consequences they might have once had for anyone daring to lie in public life".

Although too much should not be read into these political events, they do raise questions about the complex relationship between democracy, information, and libraries.

\section{Lies, damned lies, and tweets}

There is much more to the post-truth phenomenon than its manifestation in political campaigning, and, as a media phenomenon, its roots go much further back.

During the presidency of Ronald Reagan, a former Hollywood movie actor, communications scholar Neil Postman, wrote a book entitled Amusing ourselves to death: public discourse in 
the age of show business (Postman, 1986). Its central theme is stated on the first page, where he evokes

...a culture in which all public discourse increasingly takes the form of entertainment. Our politics, religion, news, athletics, education and commerce have been transformed into congenial adjuncts of show business, largely without protest or even much popular notice. The result is that we are a people on the verge of amusing ourselves to death (pp.1-2).

This was before the advent of the Internet and social media, and Postman's concern was with the influence of television. He pointed to the fragmentation and trivialization of news reporting, the substitution of images for discourse, the devastating influence on culture of the television commercial, and the confusion of everything with show business. Referring to a comment by Reagan that politics is just like show business (p.125), he commented that the main business of show business is

...to please the crowd, and its principal instrument is artifice. If politics is like show business, then the idea is not to pursue excellence, clarity or honesty, but to appear as if you are, which is another matter altogether (p.126).

In light of recent events this appears eerily prescient. Similarly, Postman pointed to the epistemic shift implied by a new definition of truth provided by television, where "the credibility of the teller is the ultimate test of the truth of a proposition" (p.102). It does not matter whether the reporting is truthful, as long as the teller appears to be credible. This trend is exacerbated by the media companies' fierce competition for viewers: more viewers means higher ratings and increased advertising income. Therefore, colourful and outspoken personalities expounding outrageous views are welcome guests at talk-shows. Mr Trump's campaign exploited this very effectively, garnering a great deal of free publicity during the primary campaign (Confessore and Yourish, 2016).

The World-wide Web challenged the traditional one-to-many communication paradigm, in which a relatively small number of players pump out content to large audiences. As Chris Anderson pointed out more than a decade ago in his book, The long tail: how endless choice is creating unlimited demand (Anderson, 2002), the World-wide Web provides niches for any group sharing a common interest, no matter how esoteric. The downside is that, surfing the Web, users can find support for any beliefs they choose to hold, no matter how "alternative". Initially the Internet was seen as a force for the good and idealized as "an unfettered civic forum: a space where disparate views, ideas and conversations could constructively converge" (Rainie et al., 2017). Commercial and political motives soon intruded, and sometimes coincided. A recent investigation into a number of "hyper-partisan websites" with diametrically opposed ideologies, which were peddling fake news, found that they were being published covertly by the same owners, presumably motivated by financial rewards rather than ideology (Silverman, 2017).

The impact of what is now referred to as Web 1.0, which offered "flat data" and allowed only limited interaction between the sites and web-users, pales into insignificance in comparison with the disruptive impact of Web 2.0, which allowed and encouraged increased interaction between sites and users, and, importantly, between users. Social media are a striking feature, of Web 2.0 (cf. Cormode and Krishnamurthy, 2008). Since Anderson wrote about the "long tail', there has been a vast expansion of social media, which allow individuals to create and share content with other individuals - many-to-many communication, in comparison with the one-to-many communication of broadcast media. Facebook was launched in 2004, Twitter in 
2006, and Instagram in 2010. The advent of the smartphone allowed users to access the Internet - and social media - at all times of the day, regardless of where they were, especially since the advent of the Apple iPhone and Android phones (McCarty, 2011).

Correspondingly, social media sites have boomed. In April 2017 Facebook, the largest social media network site, had 1,968 million users (Statista, 2017), The Pew Research Center found that by 2015 nearly two-thirds of American adults were using social networking sites, compared to just 7\% in 2005 (Perrin, 2015). The pattern is replicated in many countries around the world. While the social media platforms can provide a level playing field for information sharing and communal activities, there is growing concern about their potential harmful effects. For example, Twitter has been found to privilege "discourse that is simple, impulsive, and uncivil"; this medium was used effectively by Mr Trump (Ott, 2017). A growing incidence of "trolling", involving profanity and name-calling, personal attacks, sexual harassment or hate speech, has been noted (Cheng et al., 2017). Strange conspiracy theories proliferate, such as a theory that the Sandy Hook school massacre did not take place, but was staged by the US Federal government (Finnegan, 2016).

Social media may have the effect of isolating users from alternative viewpoints in so-called "filter bubbles", where search algorithms shape search responses to known preferences of users (Andersdotter, 2017). There is also concern about the misuse of social media for promoting extremist causes, spreading fake news and hate speech, and manipulating public opinion (Rainie et al., 2017). Using artificial intelligence techniques, such manipulation can be undertaken on a very large scale. "Bots" (fake social media profiles) send large numbers of social media messages with a view to influencing public perceptions. This has been referred somewhat alarmingly as "the rise of the weaponized AI propaganda machine" (Anderson, 2017). There is evidence that these techniques were used in the Brexit "Leave" campaign (Anderson, 2017), and by the Front National in the 2017 French presidential election (Robins-Early, 2017). Haigh, Haigh and Kozak (2017) reported on efforts in Ukraine to counter large-scale peer-to-peer propaganda, which they claim to be sponsored by the Russian state. In a statement before the US Senate Select Committee on Intelligence, the Federal Bureau of Investigation (FBI) confirmed that it was investigating Russian use of "social media bots and trolls to spread disinformation" to influence the outcome of the 2016 US presidential election (Priestap, 2017).

In 2016 a Pew survey found that American voters obtained information about the presidential election from a wide range of sources: $24 \%$ found cable TV news most helpful, followed by $14 \%$ citing social media (but this was 35\% among 18-29 year-olds) "National papers in print" came third from last at just 2\% (and only 1\% among the 18-29 year-olds) (Gottfried et al., 2016). Libraries did not feature in this survey - although of course respondents could have accessed the electronic sources and print at or through their libraries. A somewhat later Pew survey (Gottfried and Shearer, 2016) showed that a majority of US adults get news on social media, and 18\% do so often. In an experimental study, the Media Insight Project 2017 of the American Press Institute found that

[w] hen Americans encounter news on social media, how much they trust the content is determined less by who creates the news than by who shares it ... Whether readers trust the sharer, indeed, matters more than who produces the article - or even whether the article is produced by a real news organization or a fictional one.... (Media Insight Project, 2017) 


\section{What or whom to trust: a new social epistemology?}

The question raised by the Media Insight Project - what determines whether readers, listeners or viewers trust content - is not limited to the political sphere, and it is not simply a product of the older or newer electronic media. It reflects a more generalized loss of faith in authorities; the result of a long historical process. It can be traced back to the first stirrings of modernity in the Protestant Reformation and the Scientific Revolution (Tarnas, 1991, chap. 5). The Enlightenment, an intellectual movement of the seventeenth and eighteenth centuries, placed emphasis on human reason: "beliefs [were] to be accepted only on the basis of reason, not on the authority of priests, sacred texts, or tradition" (Honderich, 2005, p. 253). In the nineteenth century, Darwin, Freud and Marx, among others, overturned traditional certainties, but modernism in turn was overtaken by a postmodern mode of thinking. Postmodernism can be seen as a reaction against the assumptions of modern thinking. It is characterized by "broad scepticism, subjectivism, or relativism; [and] a general suspicion of reason...". Simplistically stated, the postmodern position is that "there is no such thing as truth" (Duignan, 2014). Postmodernism has undermined the concept of authority. "If, as postmodernist philosophy contends, truth is constructed rather than given, what gives anyone the right to say one source of information is credible and another is not?" (Barclay, 2017). Widespread scholarly revisionism, e.g. by historians who call into question cherished national myths and cut revered national heroes down to size, contributes to this.

The general loss of trust in accepted truths takes multiple forms. Authority figures can no longer take respect for granted. Given a vast range of alternative medical theories and remedies, patients widely second-guess their doctors. Parents contradict their children's teachers; ministers of religion are seen as behind the times. "Citizen journalists", not inhibited by journalistic codes of conduct, compete with the mainstream media in reporting breaking news. In fact, ethical journalistic practice plays into the hands of the liars. Traditional media try to be even-handed in giving opposing views, but in doing so they give undeserved credibility to cranks ("Art of the lie", 2016). There is widespread disillusionment with politics and distrust of politicians who are accused of not keeping their promises.

All this is not new. What seems startling is the apparent dismissal of scientific evidence by elected officials, as evidenced under the Trump administration by climate science denial, the defunding of scientific infrastructure, and moves to eliminate access to climatological databases (e.g. Bravender and Hess, 2017). In US state legislatures there have been renewed moves to introduce legislation which would relativize mainstream science in educational curricula in the name of "intellectual freedom", for example by placing alternative theories such as creationism on a par with evolution (e.g. Strauss, n.d.). Problems in the scholarly communication system have not helped: the authority of scholarly literature has been undermined by the proliferation of predatory journals, the faking of results, fraudulent peer review, and problems of conducting replication studies (Barclay, 2017).

Shortly after the inauguration of President Trump, one of his senior advisers, Kellyanne Conway, achieved brief notoriety by coining a new term. Controversy having arisen about $\mathrm{Mr}$ Trump's claims, promulgated by the White House press secretary, Sean Spicer, that the crowd attending his inauguration had been much larger than that which had attended the inauguration of his predecessor, Ms Conway denied that the White House, had lied about the size of the crowd. When challenged, she asserted that Spicer had not uttered a "falsehood", but had merely given "alternative facts" (Abramson, 2017). Falsehoods have been used in propaganda since antiquity. What is alarming - and justifies the label "post-truth" - is that 
exposing falsehoods does not stop them from being repeated, does not shame the liar, and does not affect what supporters of the liar believe. Psychological studies have shown that there is an "illusory truth effect", where repetition is ultimately equated with truth. This effect is reinforced when subjects are distracted by multiple messages (Dreyfuss, 2017).

There has been much comment on the phenomenon of "fake news". In part it has been attributed to aspects of the American and global "media ecosystem" already alluded to above. Other explanations have been advanced from theories of evolutionary psychology and from empirical studies by social psychologists and political scientists (cf. Kelkar, 2017).

Explanations derived from evolutionary psychology, are broadly concerned with how the human brain developed over millions of years to cope with environmental threats, stressing the need to respond quickly to threats - if a predator is stalking us, we need to flee, not sit around discussing the possibility of a threat. The evolutionary approach also emphasizes the importance of group cohesion for survival (Kolbert, 2017). The need to belong to the group may weigh more heavily than the "truth". In order to signal their loyalty to the group, and show whose side they are on, individuals may take positions that are contrary to reason, for example, denying evolution not because they do not understand it or because it does not make sense to them, but to identify themselves as evangelical Christians (Beck, 2017). These are pessimistic and deterministic explanations, which suggest that we cannot do much to counter the acceptance and distribution of fake news by individuals, because such responses are built into the structure and functioning of the brain.

Other explanations are derived from empirical studies by social psychologists and political scientists seeking to understand why people continue to cling to factual beliefs that have been widely shown to be at variance with reality. An expectation that people will update their beliefs in response to new information, and that therefore an abundant supply of such information will lead to changes in their understanding of situations is fundamental to librarians' beliefs about the role of libraries in democracies. However, there is growing evidence that people process the same information differently. In particular, "partisan political bias" affects how people respond to information about politically significant issues: they exhibit "confirmation bias" in which they seek out information which confirms their attitudes, and "disconfirmation bias", in which they critically dispute information which is at variance with their attitudes. Increasing media coverage of an issue will not necessarily change their attitudes (Jerit and Barabas, 2012). It has been suggested that the rejection of contrary evidence may be explained with reference to the theory of cognitive dissonance: people attempt to maintain consistency among their cognitions (behaviours, attitudes, beliefs etc.). When information is presented that contradicts strongly held beliefs, this causes discomfort and may threaten the individual's self-image (Festinger et al., 2000). The individual will seek to reduce the discomfort by various strategies, such as rejecting it, avoiding it, or explaining it away (Miller et al., 2007). Consequently, people gravitate to sources that feed their beliefs and ignore or avoid sources that contradict those beliefs.

Recently much has been written about the "backfire effect", which states that, when their beliefs are challenged, people "double-down", so that repeated correction of demonstrably false assertions reinforces beliefs - and not only among uneducated people (McRaney, 2011) as demonstrated in a study by Nyhan and Reifler (2010). However, a subsequent large-scale empirical study could find no support for this. It did find that people confronted with evidence which runs contrary to their beliefs will deploy various strategies to avoid the "cognitive effort" of dealing with it, but are unlikely to make the effort to actively develop 
counter-arguments (Wood and Porter, 2016). Some experimental work suggests that, where people reject accurate information because it threatens their worldview or self-concept, greater acceptance of correct information can be achieved if it is presented in a manner that enhances their self-concept (Nyhan and Reifler, 2015). Empirical research is continuing, with mixed results. For example, while some studies have shown that correcting people's false beliefs may be ineffective or counter-productive, other studies indicate that, in particular circumstances, corrective information may be effective in reducing misperceptions (Nyhan, 2016).

This brief overview cannot nearly do justice to a rapidly growing literature. While the alarm about the susceptibility of people to false beliefs and about the persistence of these beliefs in spite of corrective information, may be excessive, it is clear that what has been called the post-truth phenomenon has many dimensions. This has implications also for the role of libraries in providing information for democratic governance - a role which has to be seen in relation to many players and factors. Figure 2 presents a more pessimistic picture than Figure 1 of the dissemination and reception of political information and suggests that libraries play a more peripheral role than the profession's claims.

Figure 2: Revised assumptions about relationships between libraries, information and democracy

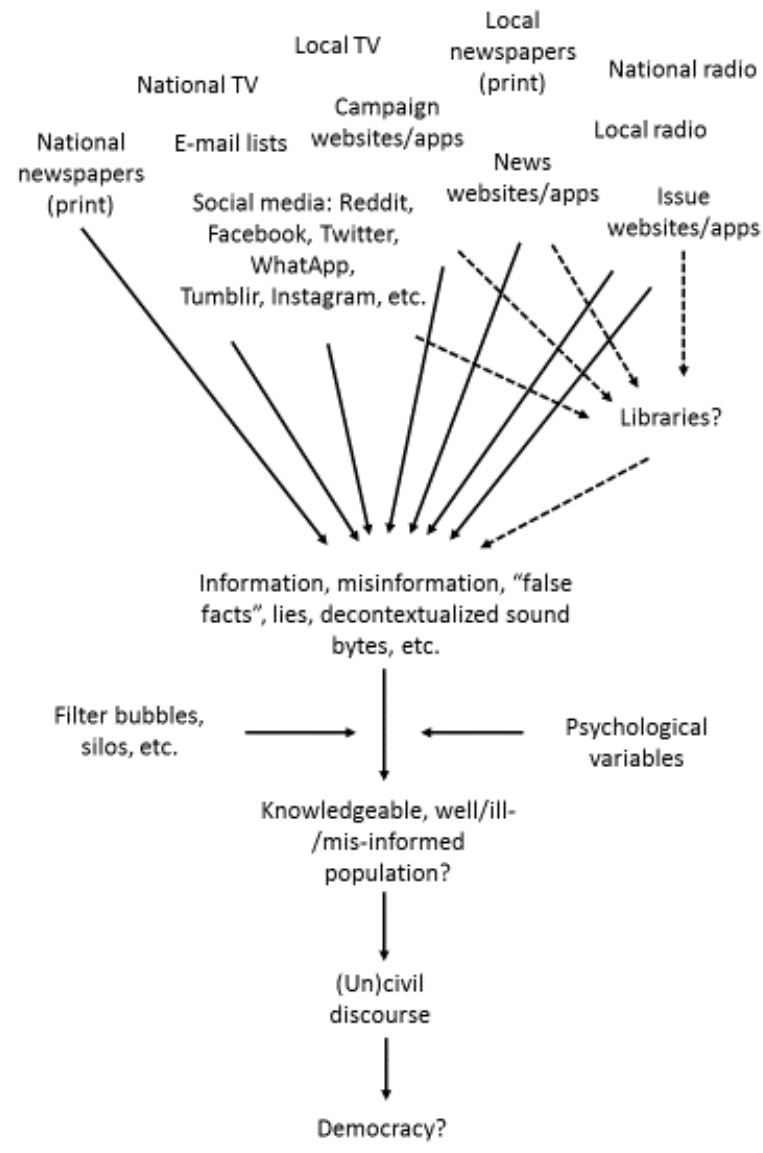

Figure produced using MS PowerPoint, copy of PowerPoint file attached 


\section{What can librarians do?}

In the USA librarians are responding to the "fake news' situation as part of a more general response to perceived threats to libraries' core values of diversity and inclusion. In the State of America's libraries report 2017 (American Library Association, 2017, pp. 10-11) the ALA emphasized public libraries' support for equal access to information, intellectual freedom, and inclusion. Various actions were launched in response to the perceived threats. These included issuing welcoming messages in library signage and social media, creating reading lists on "hot" topics, community education in spotting "fake news", and outreach to immigrants and marginalized groups. The ALA pointed out that core services such as "supporting literacy and information access, helping learners of all ages achieve educational success, and assisting immigrants to become citizens and engage with their communities" are more important than ever. It is necessary to consider these and other actions and responses by librarians in light of the challenges of the multidimensional post-truth phenomenon. Some reflections follow.

\section{Building collections}

Librarians have long been concerned with providing users with collections offering credible and authoritative information. Traditionally, in building collections, librarians attempt to maintain neutrality and not take sides in arguments. In a recent article on "fighting fake news", Paula Wilson (2017), a librarian, stated that, "[a]s librarians, we approach each and every question with the utmost professionalism. We cover all perspectives of a subject and gather multiple sources so our researchers can come to the most truthful conclusion". She also recommended that librarians be "mindful of your sources' political leanings by providing balanced perspectives and viewpoints or sticking to middle-of-the road publications" (n.p.). These recommendations embody a number of epistemic assumptions, e.g. that:

- users come with the mindset and intentions of "researchers";

- "truthful conclusions" are more likely to be arrived at if multiple sources are provided;

- librarians are equipped to identify the political leanings of the sources;

- librarians actively scrutinize individual items when selecting materials;

- librarians are equipped to determine which perspectives and viewpoints are "balanced"; and that

- "middle-of the-road publications" are most likely to lead to truth.

I need hardly point out that much of this is questionable in light of the social-psychological and political research discussed above.

\section{Providing information}

The careful evaluation needed in collection building is also called for when librarians provide information in response to reference questions. Wilson recommended that librarians should promote their "detective-like information-finding skills", so that users would know where to turn for assistance. She put together a collection of "creative ways to fight fake news". These include "the roaming reference librarian" (where librarians walk around in the library, offering assistance to clients on the floor); encouraging the use of authoritative information from collections of local and national government documents); and offering multiple sources from the library's online full-text databases) (Wilson, 2017, p. n.p.). The caveats raised in relation to the previous paragraph also apply here. 


\section{Educating users}

Information literacy has been a major thrust in librarianship since the 1980s. Predictably, the highly publicized advent of fake news has prompted calls for librarians to redouble their efforts to educate users in the critical evaluation of information sources, critical thinking and critical media literacy, A specific response has been the dissemination of guidelines for detecting fake news and related forms of falsehood. A recent example was an infographic, "How to spot fake news" produced and disseminated internationally by IFLA (Andersdotter, 2017). This listed eight questions to ask when evaluating the credibility of a news item, for example: "Check the author: do a quick search on the author. Are they credible? Are they real?"

This approach is by no means new. Two decades ago Carl Sagan created a "baloney detection kit" for detecting truth claims (Sagan, 1996). More recently two professors at the University of Seattle proposed a one-semester course less elegantly entitled, "Calling Bullshit in the Age of Big Data". It is mainly concerned with falsehood in science and scholarship, where "bullshit" is defined as "language, statistical figures, data graphics, and other forms of presentation intended to persuade by impressing and overwhelming a reader or listener, with a blatant disregard for truth and logical coherence". One of the learning objectives states that, after taking the course, the student should be able to "'[p]rovide your crystals-andhomeopathy aunt or casually racist uncle with an accessible and persuasive explanation of why a claim is bullshit" (Bergstrom and West, 2016). In light of the findings of social psychologists and political scientists, this naïve claim itself verges on bullshit.

Such naivete also appears in other kits and guidelines on how to detect fake news. In January 2017, in response to widespread concern and to criticism that Facebook had contributed to the dissemination of fake news, the company rolled out a large-scale, media literacy campaign, the News Literacy Project, to help Facebook clients to "become informed users of news and information" (News Literacy Project, 2017). While the initiative has been widely welcomed, there has also been critical comment on Facebook's ten "tips to spot false news", which are accessed via a link to Facebook's Help Center. In a critique of the tips, Caulfield (2017) pointed out that this approach has been used for two decades in American schools and colleges, and that there is no evidence that it has worked. The tips, Caulfield argues, are the opposite of what expert fact-checkers do, and can do real harm because they play into the hands of sophisticated propagandists. For example, today the use of bots by propagandists invalidates the old advice to place more credence in news items that appear in multiple sources. Fake news detection kits and programmes are not a panacea. They need to be assessed critically to determine whether they are relevant to the contemporary media environment, and they should form part of more comprehensive critical media literacy programmes, in which librarians should form partnerships with educators at all levels (Barclay, 2017) - not "one-shot information literacy training sessions" but "full programs with embedded librarians" (Banks, 2016).

\section{Refuting fake news}

Independent political fact-checking organizations, a phenomenon of the new millennium, first emerged in the USA and have proliferated world-wide since 2010. It is estimated that over 110 such groups are currently operating (Graves and Cherubini, 2016). Some research on fact-checking suggests that devoting time and energy to checking facts and rebutting lies may be counterproductive since the rebuttals keep the disputed claims in the limelight ("Art of the lie", 2016). Fact-checking requires painstaking work, while disseminators of fake news are highly active and inevitably ahead (Shao et al., 2016). In light of the earlier discussion of 
empirical studies in social psychology and political science, one is tempted to question the practical value of the fact-checking activity. However, there is some evidence that correcting misinformation by means of fact-checking has "modest but positive effects" (Graves and Cherubini, 2016, n. iv). Librarians generally take a much longer view than do journalists or social media contributors. From a librarian's perspective fact checking and correction of misinformation are important for the historical record, ensuring that if nothing else, future scholars will be able to assess current events objectively, or at least, from multiple angles.

Fact-checking requires considerable professional expertise and resources, and entails distinctive rules, routines and best practices. It is not a field for amateurs. A book-length study of fact-checking organizations by Lucas Graves (2016) does not mention libraries or librarians, and fact-checking has not emerged as a library activity per se. However, within their traditional sphere of competence, librarians have actively promoted consumption of fact-checking sources. A cursory Google search turns up large numbers of library guides, library research guides and libguides, mainly on the websites of college and university libraries. A page on the website of the Library of the College of Staten Island, City University of New York, entitled "Fake news - how the library can help", outlines this library's contribution: a library research guide [3], an online tutorial with a quiz, workshops on offer in the Fall and Spring Semesters, a course on how to evaluate information sources, and of course the possibility of conducting searches on the topic of fake news in the Library's online databases (Garvey, 2017). Valuable as this may be, it is essentially within the domain of information literacy discussed earlier. What appears to be missing so far, is reporting on what libraries may be doing to support the fact-checkers and on the library as a resource for factchecking. Could this be because fact-checking is mostly concerned with very recent information that is more likely to be found on the Web than in library finding aids? Or because, in the time-pressured world of fact-checkers, libraries and librarians simply do not come to mind?

\section{Data rescue}

As the inauguration of President Trump drew near in January 2017, Trump's known scepticism regarding anthropogenic climate change gave rise to concern in the scientific community, as did news of proposed budget cuts affecting government agencies which manage large scientific databases in various fields (Harmon, 2017). Reports that officials of the US Environment Protection Agency (EPA) had been instructed to take down web pages referring to climate change caused great alarm among climate change activists and scientists who rely on data that can be accessed via Federal websites. After a considerable backlash from the scientific community and civil society, these instructions appear to have been rescinded (Bravender and Hess, 2017). Nevertheless, librarians joined academics, coders and concerned citizens who gathered in groups at data rescue events or "hackathons" in various places, many of them libraries, to methodically download, document and preserve copies of federal databases, while activist groups were working on building systems to monitor ongoing changes to government websites (Molteni, 2017). Some of the reporting on these events was rather sensational, under headlines such as "Rogue scientists race to save climate science from Trump" (Schlanger, 2017). It remains to be seen whether libraries will develop a long-term role in the curation of the rescued data.

\section{Safe spaces}

Libraries, especially public libraries, have long been thought to provide safe spaces where people of all ages, genders, religious beliefs, political persuasions, etc., are welcome, feel comfortable and are free to access information resources without harassment and 
discrimination (Wexelbaum, 2016). Following the recent divisive election in the USA, there has been renewed emphasis on the library as a safe public space. Alvarez (2017) argued that in an "age of fake news", libraries have a role to play as venues for "respectful and constructive dialogue", where all are welcome. For this, it is important that they cultivate the trust of their communities and advocate for libraries as trusted community resources. Much as librarians strive to keep at the forefront technologically, to a considerable extent they remain custodians and providers of slower moving but less ephemeral content. This is not necessarily a disadvantage. Libraries provide continuing access to the records of our time. As a non-partisan space, a bit boring perhaps, but trustworthy, the library provides a space for reflection, a haven for civility and rationality, and a home for contrarian thinkers.

\section{Conclusion}

The post-truth phenomenon is complex. It is not in the first place an information or knowledge deficit problem, but a problem of contemporary social epistemology: what we understand by facts, how people come to believe what they consider to be true, and how this may shape their behaviour. There are no simple antidotes to fake news. Given the evolving media ecosystem and the social psychology of the reception of fake news, antidotes such as correcting misinformation, distributing fake news detection kits, and offering information literacy programmes, valuable as they are, will not suffice as remedies. They primarily address the cognitive dimension of knowledge and reasoning rather than the affective dimension of emotions, beliefs and allegiances. Furthermore, concentrating on remedies at the level of the individual is inadequate to the extent that it ignores the social dimension.

Four implications for libraries are suggested. First, we need to revise our understanding - our concepts and our rhetoric - of the relationship between libraries, information and democracy. Second, because the problem is so much bigger than libraries, it is through partnerships with other players such as educators, journalists and media that librarians can make their most useful contributions. Third, libraries should exert the soft power they have as trusted, nonpartisan community resources, and they should nurture this trust. Fourth, trust in libraries is related to their long-term constancy amid the flux of current events, ephemeral messages and constantly shifting attention. Libraries have a long time horizon. This is valuable, because there are no quick fixes. We are in this for the long haul.

\section{Endnotes}

[1] There has been some discussion as to whether one may legitimately call Mr Trumps untruths lies (e.g. Barry, 2017; Johnson (pseud.), 2017). In this writer's opinion, a person aspiring to public office who knowingly or carelessly makes false statements in public debate concerning matters of great public import, about which he/she claims to be knowledgeable, is a liar.

[2] I note in passing that the cute terminology used by Fact Checker's (using "Pinocchios" as units of measurement of falsehood) and Politifact ("pants on fire") trivializes the problem.

[3] http://guides.library.csi.cuny.edu/fake-news. 


\section{Declaration of conflicting interests}

The author declares no potential conflict of interest with respect to the research, authorship and/or publication of this article.

\section{Funding}

The author received no financial support for the research, authorship, and/or publication of this article.

\section{References}

Abramson, J. (2017), “Sorry, Kellyanne Conway. 'Alternative facts' are just lies”, The Guardian, 23 January, available at: https://www.theguardian.com/commentisfree/2017/jan/23/kellyanne-conwayalternative-facts-lies (accessed 23 January 2017).

Alvarez, B. (2017), "Public libraries in the age of fake news", Public Libraries Online, 11 January, available at: http://publiclibrariesonline.org/2017/01/feature-public-librariesin-the-age-of-fake-news/ (accessed 17 June 2017).

American Library Association. (2017), "State of America's libraries report 2017", edited by Rosa, K.S. American Libraries Special Issue, available at: http://edition.pagesuiteprofessional.co.uk/Launch.aspx?EID=aa5e87ed-c5a5-40f3-b4d2-c699ad53869d (accessed 23 April 2017).

Andersdotter, K. (2017), "Alternative facts and fake news - verifiability in the Information Society", IFLA Library Policy and Advocacy Blog, 27 January, available at: https://blogs.ifla.org/lpa/2017/01/27/alternative-facts-and-fake-news-verifiability-inthe-information-society/ (accessed 15 June 2017).

Anderson, B. (2017), "The Rise of the Weaponized AI Propaganda Machine", Scout: Science Fiction + Journalism, 12 February, available at: https://medium.com/join-scout/therise-of-the-weaponized-ai-propaganda-machine-86dac61668b (accessed 30 May 2017).

Anderson, C. (2002), The Long Tail: How Endless Choice Is Creating Unlimited Demand, Random House, London.

"Art of the lie". (2016), The Economist, 10 September, available at: http://www.economist.com/news/leaders/21706525-politicians-have-always-lieddoes-it-matter-if-they-leave-truth-behind-entirely-art (accessed 24 May 2017).

Banks, M. (2016), "Fighting Fake News", American Libraries Magazine, 27 December, available at: https://americanlibrariesmagazine.org/2016/12/27/fighting-fake-news/ (accessed 6 January 2017).

Barclay, D.A. (2017), "The challenge facing libraries in an era of fake news", The Conversation, 5 January, available at: http://theconversation.com/the-challengefacing-libraries-in-an-era-of-fake-news-70828 (accessed 7 January 2017).

Barry, D. (2017), "In a swirl of 'untruths' and 'falsehoods,' calling a lie a lie", The New York Times, 25 January, available at: https://www.nytimes.com/2017/01/25/business/media/donald-trump-lie-media.html (accessed 23 May 2017). 
BBC news. (2016), "Libraries lose a quarter of staff as hundreds close", BBC News, 29 March, available at: http://www.bbc.com/news/uk-england-35707956 (accessed 30 March 2016).

Beck, J. (2017), “This article won't change your mind”, The Atlantic, 13 March, available at: https://www.theatlantic.com/science/archive/2017/03/this-article-wont-change-yourmind/519093/ (accessed 15 March 2017).

Bergstrom, C.T. and West, J. (2016), "Calling Bullshit in the age of big data", Calling Bullshit.org, available at: http://callingbullshit.org/index.html (accessed 27 January 2017).

Bhattacharya, S. (2016), "Why we're funny about facts and prefer emotions", New Scientist, 3 August, available at: https://www.newscientist.com/article/mg23130850-500-whywere-funny-about-facts-and-prefer-emotions/ (accessed 26 May 2017).

Bravender, R. and Hess, H. (2017), "Trump officials suspend plan to delete EPA climate web pages", Science, 25 January, available at:

http://www.sciencemag.org/news/2017/01/trump-officials-suspend-plan-delete-epaclimate-web-page (accessed 26 January 2017).

Caulfield, M. (2017), "Facebook's news literacy advice is harmful to news literacy", Medium, 13 April, available at: https://medium.com/@holden/facebooks-newsliteracy-advice-is-harmful-to-news-literacy-3b354919b14d (accessed 26 April 2017).

Chaffin, J. (2016), "EU referendum: a contest between economics and emotion", Financial Times, 23 June, available at: https://www.ft.com/content/52a2fc22-388f-11e6-9a0582a9b15a8ee7 (accessed 26 May 2017).

Cheng, J., Danescu-Niculescu-Mizil, C. and Bernstein, M. (2017), "Why people troll, according to science", Business Insider, 2 March, available at: http://www.businessinsider.com/find-out-why-any-of-us-are-capable-of-trolling2017-3 (accessed 30 May 2017).

Confessore, N. and Yourish, K. (2016), "\$2 billion worth of free media for Donald Trump", The New York Times, 15 March, available at: https://www.nytimes.com/2016/03/16/upshot/measuring-donald-trumps-mammothadvantage-in-free-media.html (accessed 30 May 2017).

Cormode, G. and Krishnamurthy, B. (2008), "Key differences between Web 1.0 and Web 2.0", First Monday, Vol. 13 No. 6, available at: http://firstmonday.org/ojs/index.php/fm/article/view/2125 (accessed 30 May 2017).

Dreyfuss, E. (2017), "Want to make a lie seem true? Say it again. and again. and again", WIRED, 11 February, available at: https://www.wired.com/2017/02/dont-believe-liesjust-people-repeat/ (accessed 26 May 2017).

Duignan, B. (2014), "Postmodernism (Philosophy)", Encyclopedia Britannica, available at: https://www.britannica.com/topic/postmodernism-philosophy (accessed 31 May 2017).

Festinger, L., Riecken, H.W. and Schachter, S. (2000), "Unfulfilled propecies and disappointed messiahs", in Stone, J.R. (Ed.), Expecting Armageddon: Essential Readings in False Prophecy, Routledge, London, pp. 31-54.

Finnegan, W. (2016), "Why won't Donald Trump denounce Sandy Hook deniers?", The New Yorker, 22 November, available at: http://www.newyorker.com/news/dailycomment/why-wont-donald-trump-denounce-sandy-hook-deniers (accessed 31 May 2017).

Garvey, M. (2017), "Fake news- how the library can help", CSI Library Newsletter, 25 May, available at: http://www.library.csi.cuny.edu/blogs/newsletter/2017/05/25/fake-newshow-the-library-can-help/ (accessed 17 June 2017). 
Gottfried, J., Barthel, M., Shearer, E. and Mitchell, A. (2016), "The 2016 presidential campaign - a news event that's hard to miss", Pew Research Center's Journalism Project, 4 February, available at: http://www.journalism.org/2016/02/04/the-2016presidential-campaign-a-news-event-thats-hard-to-miss/ (accessed 23 May 2017).

Gottfried, J. and Shearer, E. (2016), "News Use Across Social Media Platforms 2016", Pew Research Center's Journalism Project, 26 May, available at: http://www.journalism.org/2016/05/26/news-use-across-social-media-platforms-2016/ (accessed 6 January 2017).

Graves, L. (2016), Deciding What's True: The Rise of Political Fact-Checking in American Journalism, Columbia University Press, New York.

Graves, L. and Cherubini, F. (2016), "The rise of fact-checking sites in Europe", Digital News Report, available at: http://www.digitalnewsreport.org/publications/2016/risefact-checking-sites-europe/ (accessed 17 June 2017).

Haigh, M., Haigh, T. and Kozak, N.I. (2017), “Stopping fake news” [preprint], Journalism Studies, pp. 1-26.

Harmon, A. (2017), "Activists rush to save government science data - if they can find it", The New York Times, 6 March, available at: https://www.nytimes.com/2017/03/06/science/donald-trump-data-rescue-science.html (accessed 9 March 2017).

Honderich, T. (Ed.). (2005), Oxford Companion to Philosophy, 2nd ed., Oxford University Press, Oxford.

Jerit, J. and Barabas, J. (2012), "Partisan perceptual bias and the information environment", Journal of Politics, Vol. 74 No. 3, pp. 672-684.

Johnson (pseud.). (2017), "A taxonomy of dishomesty”, The Economist, Vol. 422 No. 9028, p. 71.

Kelkar, S. (2017), “Three perspectives on 'fake news"”, Platypus: The CASTAC Blog, 9 May, available at: http://blog.castac.org/2017/05/on-fake-news/ (accessed 31 May 2017).

Kolbert, E. (2017), "Why facts don't change our minds", The New Yorker, 27 February, available at: http://www.newyorker.com/magazine/2017/02/27/why-facts-dontchange-our-minds (accessed 3 March 2017).

Kranich, N.C. (Ed.). (2001a), Libraries \& Democracy: The Cornerstones of Liberty, American Library Association, Chicago.

Kranich, N.C. (2001b), "Quotes about libraries and democracy”, ALA American Library Association, available at: http://www.ala.org/aboutala/governance/officers/past/kranich/demo/quotes (accessed 26 May 2017).

Luu, C. (2016), "The collapse of meaning in a post-truth world”, JSTOR Daily, 21 December, available at: https://daily.jstor.org/collapse-of-meaning-in-a-post-truth-world/ (accessed 28 April 2017).

McCarty, B. (2011), "The history of smartphones", The Next Web, 6 December, available at: https://thenextweb.com/mobile/2011/12/06/the-history-of-the-smartphone/ (accessed 30 May 2017).

McRaney, D. (2011), “The backfire effect", You Are Not So Smart, 10 June, available at: https://youarenotsosmart.com/2011/06/10/the-backfire-effect/ (accessed 14 June 2017).

Media Insight Project. (2017), "Who shared it? How Americans decide what news to trust on social media", "The Media Insight Project, available at: http://mediainsight.org/PDFs/Trust\%20Social\%20Media\%20Experiments\%202017/ MediaInsight_Social\%20Media\%20Final.pdf (accessed 22 March 2017). 
Miller, M.K., Clark, J.D. and Jehle, A. (2007), "Cognitive dissonance theory (Festinger)", in Ritzer, G. (Ed.), Blackwell Encyclopedia of Sociology, Blackwell Publishing Ltd, Oxford, available at:https://doi.org/10.1111/b.9781405124331.2007.x.

Molteni, M. (2017), "Diehard Coders Just Rescued NASA's Earth Science Data", WIRED, available at: https://www.wired.com/2017/02/diehard-coders-just-saved-nasas-earthscience-data/ (accessed 16 February 2017).

News Literacy Project. (2017), "Facebook to support the News Literacy Project on public service ad campaign", The News Literacy Project, 11 January, available at: http://www.thenewsliteracyproject.org/facebook-support-news-literacy-projectpublic-service-ad-campaign (accessed 16 June 2017).

Nyhan, B. (2016), "Fact-checking can change views? We rate that as mostly true", The New York Times, 5 November, available at: https://www.nytimes.com/2016/11/06/upshot/fact-checking-can-change-views-werate-that-as-mostly-true.html (accessed 16 June 2017).

Nyhan, B. and Reifler, J. (2010), "When corrections fail: the persistence of political misperceptions", Political Behavior, Vol. 32 No. 2, pp. 303-330.

Nyhan, B. and Reifler, J. (2015), "The roles of information deficits and identity threat in the prevalence of misperceptions", available at: https://pdfs.semanticscholar.org/62c0/961bb310e215dfd27c8a0893c31cd60d27e4.pdf (accessed 14 June 2017).

Ott, B.L. (2017), "The age of Twitter: Donald J. Trump and the politics of debasement", Critical Studies in Media Communication, Vol. 34 No. 1, pp. 59-68.

Oxford Dictionaries. (2017), "Word of the Year 2016", Oxford Dictionaries | English, available at: https://en.oxforddictionaries.com/word-of-the-year/word-of-the-year2016 (accessed 24 May 2017).

Perrin, A. (2015), Social Media Usage: 2005-2015, Pew Research Center, available at: http://www.pewinternet.org/2015/10/08/social-networking-usage-2005-2015/ (accessed 30 May 2017).

Postman, N. (1986), Amusing Ourselves to Death: Public Discourse in the Age of Show Business, Heinemann, London.

Priestap, B. (2017), "Assessing Russian activities and intentions in recent elections", Federal Bureau of Investigation, Testimony, , 21 June, available at: https://www.fbi.gov/news/testimony/assessing-russian-activities-and-intentions-inrecent-elections (accessed 21 June 2017).

Rainie, L., Anderson, J. and Albright, J. (2017), "The future of free speech, trolls, anonymity and fake news online", Pew Research Center: Internet, Science \& Tech, 29 March, available at: http://www.pewinternet.org/2017/03/29/the-future-of-free-speech-trollsanonymity-and-fake-news-online/ (accessed 30 May 2017).

Robins-Early, N. (2017), "Far-Right Bots Are The Secret Of Marine Le Pen's Social Media Boom", Huffington Post, 7 March, available at: http://www.huffingtonpost.com/entry/marine-le-pen-botstwitter_us_58bc21c1e4b05cf0f40125d6 (accessed 12 March 2017).

Sagan, C. (1996), "The fine art of baloney detection", The Demon-Haunted World: Science as a Candle in the Dark, available at: http://www.inf.fuberlin.de/lehre/pmo/eng/Sagan-Baloney.pdf (accessed 24 March 2017).

Schlanger. (2017), "Rogue scientists race to save climate data from Trump", WIRED, 17 January, available at: https://www.wired.com/2017/01/rogue-scientists-race-saveclimate-data-trump/ (accessed 17 June 2017). 
Shao, C., Ciampaglia, G.L., Flammini, A. and Menczer, F. (2016), "Hoaxy: a platform for tracking online misinformation", arXiv, 4 March, available at: http://arxiv.org/pdf/1603.01511v1.pdf (accessed 15 March 2016).

Silverman, C. (2017), "This is how your hyperpartisan political news gets made", BuzzFeed, 28 February, available at: https://www.buzzfeed.com/craigsilverman/how-thehyperpartisan-sausage-is-made (accessed 1 March 2017).

Statista. (2017), "Most famous social network sites worldwide as of April 2017, ranked by number of active users (in millions)", Statista, April, available at: https://www.statista.com/statistics/272014/global-social-networks-ranked-by-numberof-users/ (accessed 30 May 2017).

Strauss, V. (n.d.). “An 'alternative facts' South Dakota bill sparks fears for science education in the Trump era", Washington Post, available at: https://www.washingtonpost.com/news/answer-sheet/wp/2017/02/05/an-alternativefacts-south-dakota-bill-sparks-fears-for-science-education-in-the-trump-era/ (accessed 9 February 2017).

Tarnas, R. (1991), The Passion of the Western Mind: Understanding the Ideas That Have Shaped Our World View, Ballantine books, New York.

Wahl-Jorgensen, K. (2016), "The emotional politics of the EU Referendum: Bregrexit [sic] and beyond", EU Referendum Analysis 2016, 3 July, available at: http://www.referendumanalysis.eu/eu-referendum-analysis-2016/section-8-voters/theemotional-politics-of-the-eu-referendum-bregrexit-and-beyond/ (accessed 26 May 2017).

Wang, A. (2016), “'Post-truth' named 2016 word of the year by Oxford Dictionaries”, Washington Post, 16 November, available at: https://www.washingtonpost.com/news/the-fix/wp/2016/11/16/post-truth-named2016-word-of-the-year-by-oxford-dictionaries/ (accessed 7 January 2017).

Wexelbaum, R. (2016), "The library as safe space", Advances in Library Administration and Organization, Vol. 36, pp. 37-78.

Wilson, P. (2017), "Creative ways to fight fake news", Public Libraries Online, 9 February, available at: http://publiclibrariesonline.org/2017/02/creative-ways-to-fight-fakenews/ (accessed 12 February 2017).

Wood, T. and Porter, E. (2016), The Elusive Backfire Effect: Mass Attitudes' Steadfast Factual Adherence, SSRN Scholarly Paper No. ID 2819073, Social Science Research Network, Rochester, NY, available at: https://papers.ssrn.com/abstract=2819073 (accessed 16 June 2017). 